Research Article

\title{
Formulation, Development and Characterization of Herbal Soap Using Borassus flabellifer and Curcuma zedoaria.
}

\author{
Devipriya Nisha P*, Nivetha L, Deepak Kumar U \\ * Department of Biotechnology, PSG College of Arts and Science, Coimbatore, India. \\ *Corresponding author's E-mail: devipriyanisha@gmail.com
}

Received: 27-05-2021; Revised: 19-07-2021; Accepted: 26-07-2021; Published on: 15-08-2021.

\begin{abstract}
Bacterial infections are most common in humans. The herbs are known to possess various potentials like anti-inflammatory, antibacterial and antifungal properties which are explored for ages and incorporated into various forms, for human use. One such usage is formulation of herbal soap that is used not only for treating microbial infections, but also for using it on daily basis. The aim and objective of the present study is to investigate the presence of phytochemicals in the extract and to formulate an herbal soap using the extract of seed coat of B.flabellifer and rhizome of C.zedoaria and explore its properties. Both the aqueous extracts were equally mixed with soap base and the formulated soap was further subjected to physicochemical characterizations such as color, odor, texture, total fatty matter, foam test, moisture content, total alkali content and $\mathrm{pH}$. The antioxidant activity assay was done for the herbal soap and its IC50 value was low, but plant possess antioxidant activity. The antibacterial activity of the formulated soap was checked in agar well diffusion method and it shows active against the $S$. aureus and E.coli. The results shows that the soap possess good antimicrobial activity. Antimicrobial and antifungal compound were present in the herbal extract confirmed by GC MS analysis.
\end{abstract}

Keywords: Herbal soap, B.flabellifer, C.zedoaria, Medicinal plants.

QUICK RESPONSE CODE $\rightarrow$

DOI:

10.47583/ijpsrr.2021.v69i02.020

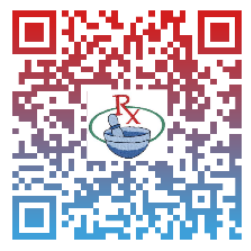

DOI link: http://dx.doi.org/10.47583/ijpsrr.2021.v69i02.020

\section{INTRODUCTION}

P

lants with medicinal properties are being used as traditional medicine from times immemorial. The extract obtained from the leaves, stem and roots of various medicinal plants have been employed as a natural remedy in curing various ailments and diseases. Even though many of the plant based products have been replaced by synthetic chemicals, the safety and efficacy of Ayurvedic products has set standards. The active constituents responsible for such medicinal values are employed topically as creams, soaps, oils and ointments for treating skin related ailments like acne, wounds, eczemas, and ring-worms, as an anti-microbial agent and for cosmetic purposes ${ }^{1}$. Nowadays, there is an increasing consumer demand for cosmetics comprising natural ingredients as healthier, organic, and ecological product ${ }^{2}$. Consumers are more and more refusing synthetic chemicals in beauty and cosmetic products. A natural soap is prepared without a non-natural surfactant, with addition of functional ingredient from natural substance, such as essential oil or plant extract.

A natural soap may be generally divided based on the production method into: a melt - pour soap, a hot process soap, and a cold process soap. The hot process soap is called a transparent or translucent soap. The soap has good detergency or cleansing power, good moisturizing effects, long-lasting fragrance, and less of irritant. Herbal soaps are prepared by adding various dried herbs, flowers and stems into soap base. Herbs are the natural products could be found in the treatment of almost all diseases and skin problems owing to their high medicinal value, cost effectiveness, availability and compatibility ${ }^{3,4}$. Hence it can be used in soap base. The attribute of a soap includes gentleness on the skin, rich lather, protection against various skin disorders (including rashes, eczema, scabies) treatment of skin infection (such as ringworm), protection of even skin toning and smoothness of the skin $^{5}$.

Curcuma zedoaria also known as white turmeric or zedoaria is a perennial herb found in tropical countries such as India, Japan and Thailand. It is used traditionally for the treatment of menstrual disorders, dyspepsia, vomiting ${ }^{6}$. Borassus flabellifer belongs to family Arecaceae, commonly known as palmyra palm. This plant is a tall tree (palm) growing in sandy soil and attaining height $20-30 \mathrm{~m}$ with a straight trunk. This plant is widely distributed and cultivated in tropical Asian countries like Thailand, Bangladesh, India, Myanmar, Sri Lanka, Malaysia, etc. Various parts of this plant is known to have many properties like anti-diabetic property, anti-pyretic effects, anti-inflammatory activity, etc.

The aim of the present work is to formulate a herbal soap containing the extracts of seed coat of B.flabellifer and rhizome of C.zedoaria and analyzing its physicochemical properties, anti-oxidant activity, GC-MS analysis and antimicrobial properties. 


\section{MATERIALS AND METHODS}

\section{Sample collection and extraction}

Fresh seed coat of B.flabellifer was collected, washed and shade dried for 2 weeks. The dried rhizome of C.zedoaria was purchased from local traditional folk medicine shop. Both were powdered separately and the extract was obtained using soxhlet apparatus using distilled water.

\section{Phytochemical screening analyses}

Preliminary phytochemical screening was carried out to determine the presence of various bioactive constituents like Alkaloids, anthraquinones, carbohydrates, coumarins, flavonoids, steroids and terpenoids in the aqueous extract by using standard methods. ${ }^{7}$

\section{Soap preparation}

Soap base was purchased from local market in Sivakasi. About 100g of soap base was taken and cut into pieces and melted in oven until it turns into liquid base. To it, $10 \mathrm{ml}$ aqueous extract of C.zedoria and $10 \mathrm{ml}$ aqueous extract of B.flabellifer were added. Few drops of coconut oil were also added. The mixture was poured in a cast and allowed to dry.

\section{Characterization of herbal soap (Evaluation of Soap) \\ Physicochemical evaluation of herbal soap organoleptic evaluation}

Organoleptic parameters like colour, odour and texture were evaluated manually or physically.

\section{Determination of $\mathrm{pH}$}

$2 \mathrm{~g}$ of the finished soap was dissolved in $10 \mathrm{ml}$ of distilled water and stirred till sample dissolved. The $\mathrm{pH}$ was determined using $\mathrm{pH}$ meter.

\section{Determination of foaming ability}

$2 \mathrm{~g}$ of the soap was dissolved in $50 \mathrm{ml}$ of distilled water in a $100 \mathrm{ml}$ measuring cylinder and shaken vigorously for $2 \mathrm{~min}$. It was allowed to stand for 10 min after which the height of the foam was measured. This was repeated thrice and the mean computed.

\section{Determination of total fatty matter (TFM)}

The total fatty matter test is carried out by reacting the soap with acid in the presence of hot water and measuring the fatty acids obtained. About $10 \mathrm{~g}$ of the finished soap was weighed and $150 \mathrm{ml}$ distilled water was added and heated. The soap was dissolved in $20 \mathrm{ml}$ of $15 \%$ Sulphuric acid while heating until a clear solution was obtained. Fatty acids on the surface of the resulting solution was solidified by adding $7 \mathrm{~g}$ of bee wax and is reheated. The set up was allowed to cool to form cake .Cake was removed and blotted to dry and weighed to obtain the total fatty matter using a formula:

$\% \operatorname{TFM}=(\mathrm{A}-\mathrm{X}) / \mathrm{W} \times 100$ Where; $\mathrm{A}=$ weight of wax+ oil, $\mathrm{X}=$ weight of wax, $W=$ weight of soap.

\section{Determination of moisture content}

About $10 \mathrm{~g}$ of the sample under study were accurately weighed and transferred to a tarred china dish of known weight and kept in a hot air oven at $100-105^{\circ} \mathrm{C}$ for an hour. Then, the sample was weighed along with the china dish to deduct the actual weight of tarred china dish. The weight of the content was noted to calculate the percentage moisture content.

Moisture content $=($ Difference in weight/initial weight $) x$ 100

\section{Total Alkali}

This was determined by titrating excess acid contained in the aqueous phase with standard volumetric $\mathrm{NaOH}$ solution. 1 gram of the finished soap was weighed and $5 \mathrm{ml}$ of ethanol was added, $0.5 \mathrm{ml}$ of $1 \mathrm{M} \mathrm{H} 2 \mathrm{SO} 4$ solution was added to the mixture and heated until the soap sample dissolved. The test solution was titrated against 1.0M NaOH using phenol phenolphthalein as indicator. The total alkali was obtained (AOCS, 1997).

$$
\% \text { alkali }=[(\mathrm{VA}-\mathrm{VB}) / \mathrm{W}] \times 3.1
$$

\section{Determination of anti-oxidant activity}

\section{Diphenyl Picryl Hydrazyl (DPPH) radical scavenging method:}

The antioxidant activity of the extract was determined in terms of hydrogen donating or radical scavenging ability using the stable radical DPPH, according to the method. ${ }^{8}$ Samples and Standard (ascorbic acid) were taken in various concentrations and the volume was adjusted to $1000 \mathrm{~mL}$ with methanol. About $3 \mathrm{~mL}$ of a $0.1 \mathrm{mM}$ methanolic solution of DPPH was added to the aliquots of samples and mixed well. Negative control was prepared by adding 1000 $\mathrm{mL}$ of methanol in $3 \mathrm{~mL}$ of $0.1 \mathrm{mM}$ methanolic solution of $\mathrm{DPPH}$. The tubes were allowed to stand in dark for 30 minutes at room temperature. The absorbance of the sample was measured at $517 \mathrm{~nm}$ against the blank and the percentage inhibition activity was calculated from [(AO$\mathrm{A} 1) / \mathrm{A0}] \mathrm{x} 100$, where $\mathrm{A} 0$ is the absorbance of control, and A1 is the absorbance of extract/ standard. The inhibition curves were prepared and the IC50 values were obtained.

\section{GC-MS analysis}

Plant extracts were subjected to Gas Chromatography and tmass spectroscopy (GC-MS) and the obtained spectra was analyzed. GC Model: Thermo Trace GC Ultra, MS Model: Thermo DSQ II, Ionization: Electron Impact Ionisation (EI), Chemical Ionisation ( $\mathrm{Cl}$ ), Mass Range: 1 - $1074 \mathrm{~m} / \mathrm{z}$. The column used is HP-5MS UI (cross-linked $5 \%$ methyl phenyl Silox) capillary column ( $30 \mathrm{~m} \times 0.25 \mathrm{~mm})$ and the film thickness is $0.25 \mu \mathrm{m}$. The oven temperature was increased from $50-200{ }^{\circ} \mathrm{C}$ at a rate of $10 \mathrm{oC} / \mathrm{min}$. Then, continued 200 $300^{\circ} \mathrm{C}$ at rate $30^{\circ} \mathrm{C} / \mathrm{min}$. Then post run for 10 minutes in $300^{\circ} \mathrm{C}$. Pure helium gas was used as carrier gas with a flow rate of $1 \mathrm{~mL} / \mathrm{min}$. Injector and detector temperatures were $250{ }^{\circ} \mathrm{C}$. GC-MS was done by injecting $1 \mu \mathrm{L}$ of sample $(0.1 \%$ in absolute methanol). 


\section{Anti-microbial activity}

Agar well diffusion method was used. Petriplate containing $20 \mathrm{ml}$ of Mueller Hinton agar were seeded with $24 \mathrm{~h}$ culture of Staphylococcus aureus and Escherichia coli. Five wells were created in which one acts as control and in the rest 4 wells, different concentrations of the extract were added. The plates were incubated at $37^{\circ} \mathrm{C}$ for $24 \mathrm{~h}$. The zone of inhibition was measured.

\section{RESULTS AND DISCUSSION}

\section{Phytochemical Analysis}

Phytochemical analysis of C.zedoaria revealed the presence of phytochemicals such as carbohydrates, coumarins, flavonoids, saponins, steroids and terpenoids and the analysis of the plant extract from B.flabellifer revealed the presence of phytochemicals such as alkaloids, anthraquinones, carbohydrates, phenol, tannins, protein, saponins and terpenoids which is tabulated in Table 1. Phenol is considered as an important phytochemical for health constituents. Flavonoids are largest classes of plant phenolics and are known to have good antioxidant activity.

Table 1: Phytochemical analysis

\begin{tabular}{|c|c|c|}
\hline Phytochemicals & C.zedoaria & B.flabellifer \\
\hline Alkaloids & - & + \\
\hline Anthraquinones & - & + \\
\hline Carbohydrates & + & + \\
\hline Coumarins & + & - \\
\hline Flavonoids & + & - \\
\hline Phenol and tanins & - & + \\
\hline Proteins & - & + \\
\hline Saponins & + & + \\
\hline Steroids & + & - \\
\hline Terpenoids & + & + \\
\hline
\end{tabular}

\section{Physico Chemical Evaluation of Herbal Soap}

The physicochemical properties of soap include moisture content, pH, color, Total Fatty Matter (TFM), Alkali content which are tabulated in Table 2 \& Fig 1.

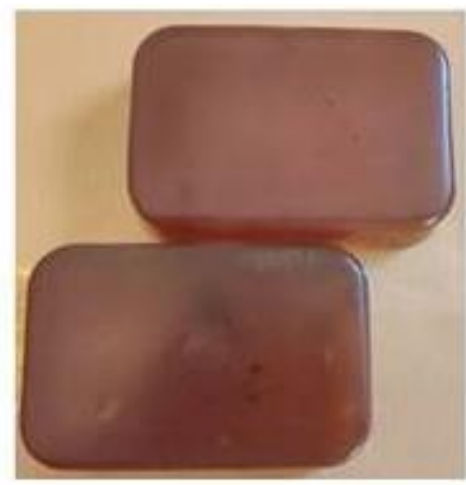

Fig 1: Herbal soap
Table 2: Physicochemical evaluation

\begin{tabular}{|c|c|c|}
\hline Parameters & Results & ${ }^{*}$ Control \\
\hline Color & Dark brown & Pink Colour \\
\hline Odor & Pleasant smell & Pleasant smell \\
\hline Texture & $\begin{array}{l}\text { Solid and } \\
\text { smooth }\end{array}$ & $\begin{array}{l}\text { Solid and } \\
\text { smooth }\end{array}$ \\
\hline $\mathrm{pH}$ & 9.02 & 9.18 \\
\hline Foaming index & $6 \mathrm{~cm}$ & $24 \mathrm{~cm}$ \\
\hline Moisture content & $26.2 \%$ & $20.23 \%$ \\
\hline Total Fatty Matter & $35 \%$ & $36.8 \%$ \\
\hline $\begin{array}{l}\text { Total Alkali } \\
\text { Content }\end{array}$ & $0.03 \%$ & $0.99 \%$ \\
\hline
\end{tabular}

*Control - Lifebuoy soap purchased from local market.

The $\mathrm{pH}$ of the herbal soap prepared was found to be 9.02 , which lies between the normal $\mathrm{pH}$ range 8-10 as reported by National Agency for Food and Drug Administration and Control (NAFDAC). The obtained $\mathrm{pH}$ value is similar to that of control soap.

The foaming index of the prepared herbal soap was found to be $6 \mathrm{~cm}$ which is low compared to control $(24 \mathrm{~cm})$. Although foam generation has little to do with cleansing ability it is of outmost importance to the consumer and therefore considered as a parameter in evaluating soaps. Total Fatty Matter (TFM) is how much fat substance the soap has, that is, it is the indication of soap quality. The more it has better the quality of the soap.

The Total Fatty Matter of the prepared herbal soap was $35 \%$ which is closer to $36.66 \pm 0.02 \%$ reported for onion oil soap $^{9}, 36.8 \%$ as shown by the control and lower than $63.75 \pm 0.07 \%$ reported for neem soap ${ }^{10}$.The differences in total fatty matter is responsible for high moisture content. Low total fatty matter values are due to the presence of unreacted $\mathrm{NaOH}$ in the mixture. ${ }^{11}$ Higher concentration of fatty acids has good effects on the skin in the sense of rehydration and overall enhanced cleansing properties.

Moisture content is a parameter that measures the shelf life of a product. High moisture content in the soap could lead to reaction of excess water with un-saponified fat to give free fatty acid and glycerol in a process called hydrolysis of soap on storage. Moisture content of the soap is $26.2 \%$, which is high comparative to standard and control (20.23\%). This might be due to the difference in soap preparation methods.

The alkali content of the soap was found to be $0.03 \%$ which is lower than $0.99 \%$ as shown by control and very much lower than $0.24 \pm 0.01 \%$ as reported for neem oil soap ${ }^{10}$. The lower the value is, better the quality of the soap. This indicates that, the prepared soap is not corrosive to the skin. The alkaline substances present, helps in neutralizing the body's protective acid mantle that acts as a natural barrier against bacteria and viruses. Healthy skin has a $\mathrm{pH}$ 5.4 to $5.9 .{ }^{12}$ The alkalinity favors detergency. ${ }^{13}$ 


\section{DPPH Analysis}

The antioxidant activity test is conducted to find out how much the soap ability in reducing free radical of DPPH. DPPH serves as a free radical compound that will react with antioxidant soap. The ability to capture the free radicals is related to the ability of a compound to donate electrons or hydrogen. Any molecule that can donate electrons or hydrogens will react and fade the DPPH color from purple to yellow to form the 1,1-diphenyl-2-picrilhidrazine compound. Ascorbic acid was used as positive control.

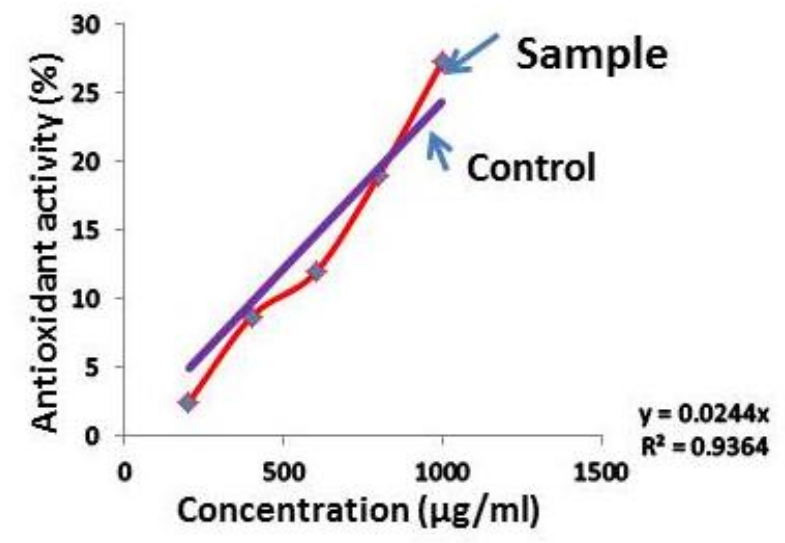

Figure 2: Antioxidant activity

Result (Fig 2) showed the percentage inhibition of DPPH radical of the herbal soap and standard at different concentrations. The IC50 values of the formulated herbal soap and ascorbic acid were found to be $2.049 \mathrm{mg} / \mathrm{ml}$ and $0.507 \mathrm{mg} / \mathrm{ml}$ respectively. Antioxidant activity is very strong if it has IC50 value less than $0.05 \mathrm{mg} / \mathrm{ml}$, strong if IC50 values between $0.05-0.10 \mathrm{mg} / \mathrm{ml}$, medium if IC50 values between $0.10-0.15 \mathrm{mg} / \mathrm{ml}$ and weak if IC50 values between $0.15-0.20 \mathrm{mg} / \mathrm{ml}^{14}$ The lower the IC50 value, higher is the scavenging activity. The IC50 represents the concentration of the sample extract required to scavenge 50\% DPPH radical. ${ }^{15}$ Thus comparing with the IC50 values obtained, the formulated herbal soap seems to have low antioxidant activity. The loss of antioxidants might be caused by the reaction temperature as antioxidants are thermally sensitive. The antioxidant properties are contributed by the presence of polyphenolics, flavonoids, vitamin C, and monophenolics making the identification and quantification of these compounds important. ${ }^{16}$ The presence of these phytochemicals in less amount might have also been a reason for low anti-oxidant activity.

\section{GC-MS Analysis}

The GC-MS analysis of the herbal soap revealed the presence of 55 compounds. The biomolecule present in high amount is Z-17-Nonadecen-1-ol acetate, And the bio molecules present in low concentration are $9 \mathrm{H}-\mathrm{Xanthen}-9$ one, 2,7-dichloro-1-hydroxy-3,6-dimethoxy-8-methyl- and 2-Chloro-4,6-di(4-methoxyphenyl) pyrimidine which is revealed in Figure $3 \& 4$. Several authors have shown that natural aromatic compounds possess important biological activities, such as antitumor, antihepatotoxic, antioxidant, anti-inflammatory, estrogenic and antibacterial activities. The components present in the herbal soap analyzed using GCMS.

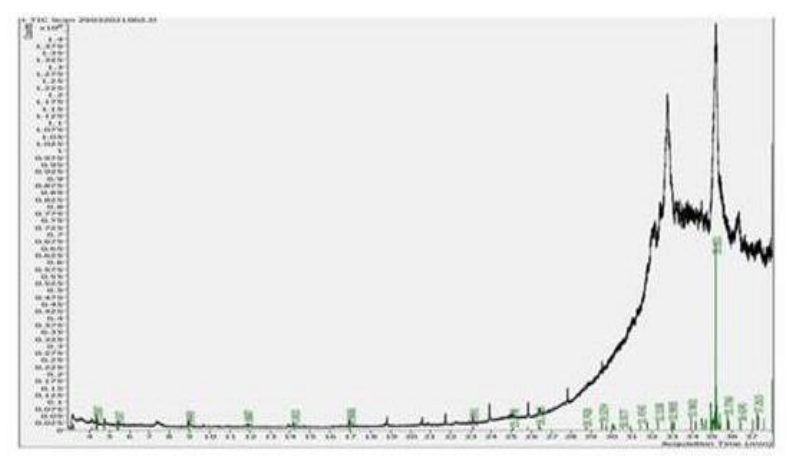

\section{Fig 3: GC MS graph of herbal soap}

Among the 55 compounds, 23 compounds were known for medicinal properties and the properties of 22 compounds were unknown. Among these, 11 compounds were antimicrobial agents, five compounds have anti-fungal activity, three compounds have anticancer activity, two compounds have anti-leukemic properties, two compounds have antiHIV properties. There were also presence of compounds having anti-oxidant properties, anti-inflammatory property, anti-allergic property, anti-protozoal activity, anti-depressant, anti-tuberculosis activity, insecticidal property, anti-mycobacterial activity and neuroprotective property.

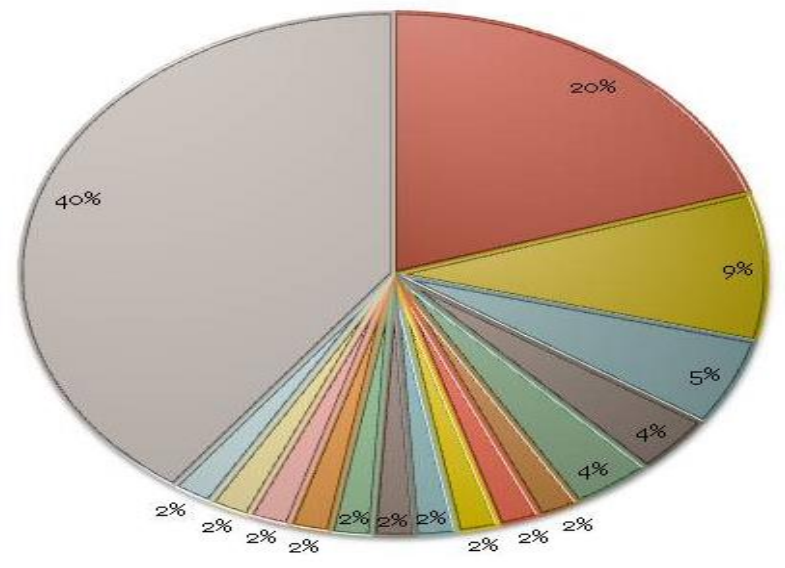

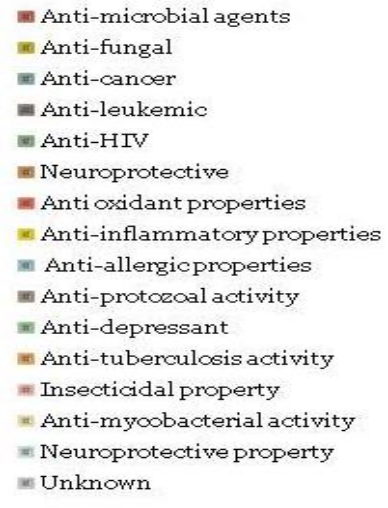

Figure 4: Pie chart showing GC MS components. 


\section{ANTI-MICROBIAL ACITVITY}

The antibacterial activity of herbal soap was determined by measuring the diameter of zone of inhibition and result was tabulated in Table 3 \& Fig 5. Gentamycin was used as positive control. The zone of inhibition of gentamicin against E.coli was $27 \mathrm{~mm}$ and S.aureus was found to be $30 \mathrm{~mm}$. The antibacterial activity of the herbal soap was found to be very significant for S.aureus as the highest zone of inhibition

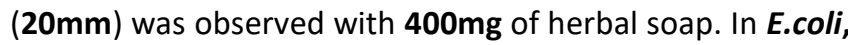
the highest zone of inhibition $(\mathbf{2 5} \mathbf{m m})$ was observed with $400 \mathrm{mg}$ of herbal soap. The zone of inhibition is in accordance with increase in concentration of the herbal soap.

Table 3: Anti-bacterial activity of herbal soap and standard drug

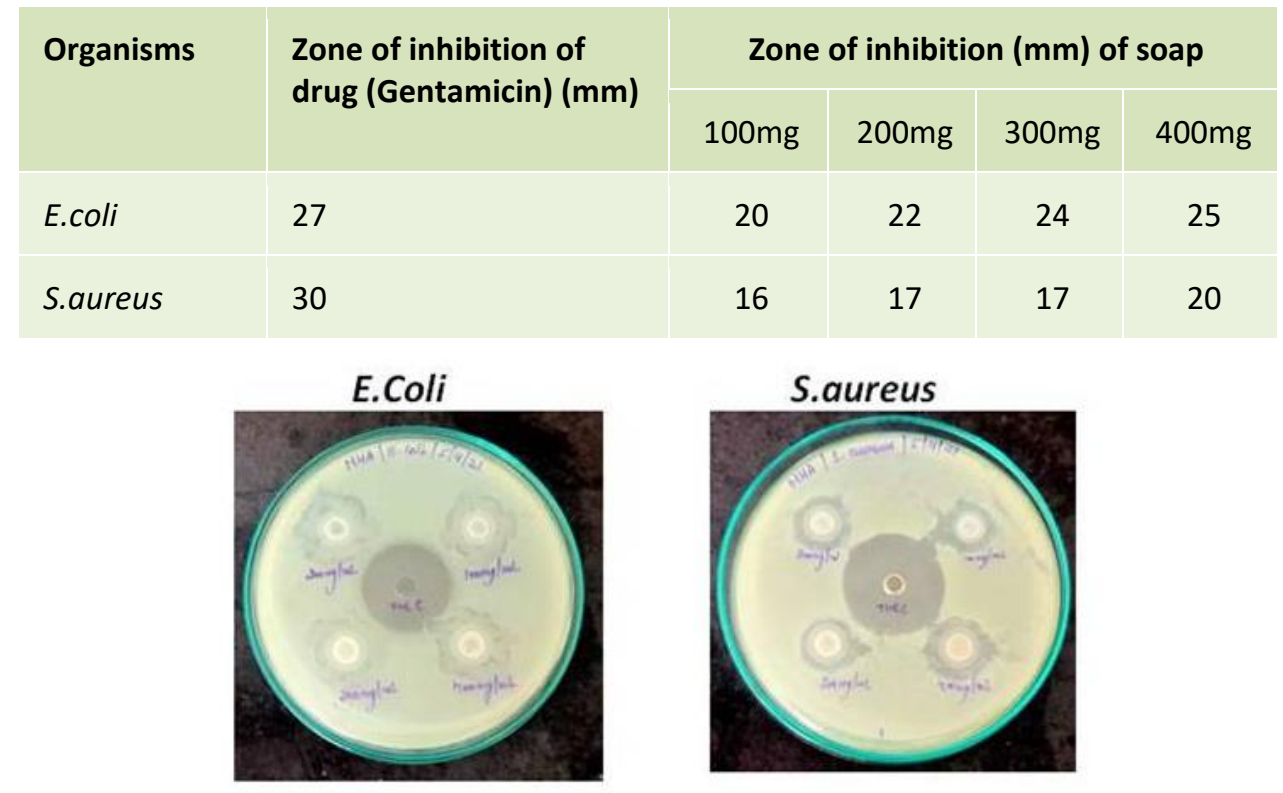

Fig 5 : Anti-microbial activity of herbal soap against E.coli and S.aureus.

\section{CONCLUSION}

In conclusion, the aqueous extracts of the plant materials shows the potential in soap formulation. The physicochemical property of the formulated soap was good and comparable to the control. GCMS analysis revealed the presence of active biomolecules having pharmacological properties and it can be used for future studies.

\section{REFERENCES}

1. Kandasamy R. Formulation of Herbal Bath Soap from Vitex negundo Leaf Extract. Journal of Chemical and Pharmaceutical Sciences. 2014; 2: 95-99.

2. Antignac E, Nohynek G J, Re T, Clouzeau J, Toutain H. Food Chem. Toxicol.2011; 49: 324-341.

3. Solanki R. Treatment of skin diseases through medicinal plants in different regions of the world. International Journal of Biomedical Research. 2011; 2(1): 73-88.

4. Saikia A.P., Ryakala V.K., Sharma P., Goswami P., Bora U. Ethnobotany of medicinal plants used by Assamese people for various skin ailments and cosmetics. Journal of Ethnopharmacology. 106(2), 2006;106(2):149-157.

5. Getradeghana B.T. Evaluation of African traditional soap. Global Journal of Pure and Applied Science. 2000; 6:174-179.
6. Prajapati N.D. Agro's Dictionary of Medicinal Plants. 1st edn. India: Agrobiosis, 2003.

7. Jeenu, Joseph L, George M, Bindhu AR. World Journal of Pharmaceutical Research. Phytochemical screening and antioxidant activity of various extracts of Clerodendru M Paniculatum Linn. 2018;7(13):555-68.

8. Zaman KA, Khalid AA. Free radical scavenging activity of some bangladeshi medicinal plants. Pharmacology online. 2015;3(12):29-32.

9. Warra AA, Wawata IG, Umar RA, Gunu, S.Y. Soxhlet extraction, Physicochemical Analysis and Cold process Saponification og Nigeria Jatropha curcas L. seed oil. Canadian J.Pure and Appl. Sci. 2012;6(1):1803-180719.

10. Mak-Mensah EE, Firempong CK. Hemical characteristics of toilet soap prepared from neem (Azadirachta indica A.Juss) seed oil. Asian Jounal of Plant Science and Research. 2011; 17:2249-7412.

11. Roila A, Salmiah A, Razmah. Properties of sodium soap derived from palm based hydroxystearic acid. J. Oil Palm Res. 2001; 13(2):33-38.

12. Gil M.I., Thomas Barberan F.A., Hess-Pierce B, Hplcroft D.M., Kader A.A. Antioxidant activity of pomegranate juice and its relationship with phenolic composition and processing. J Agri Food Chem. 2000; 48:4581-4589. 
13. Bondet V, Brand-Williams W, Berset C. Kinetics and mechanisms of antioxidant activity using the DPPH free radical method. Lebensmitt Wissenschaft Technologie Food Sci Technol. 1997;30:609-615.

14. Widyaningsih, S., Chasani, M., Diastuti, H., \& Fredyono, W. N. Liquid Soap from Nyamplung Seed Oil (Calophyllum inophyllum L) with Ketapang (Terminalia catappa L) as Antioxidant and Cardamom (Amomum compactum) as Fragrance. Molekul. 2018; 13(2):172 179.

15. Omenna, Chukwuma Emmanuel. Antioxidative activity of the almond leaves (Terminalia catappa). International Journal of Nursing, Midwife and Health Related Cases 1, 2015;2:29-40.

16. Sunitha Dontha. A review on antioxidant methods. Asian Journal of pharmaceutical and clinical research, 2016;9:18-24.

Source of Support: The author(s) received no financial support for the research, authorship, and/or publication of this article.

Conflict of Interest: The author(s) declared no potential conflicts of interest with respect to the research, authorship, and/or publication of this article.

For any question relates to this article, please reach us at: editor@globalresearchonline.net New manuscripts for publication can be submitted at: submit@globalresearchonline.net and submit_ijpsrr@rediffmail.com 